\title{
TITLE:
}

\section{What makes wild chimpanzees wake up at night?}

\author{
$\operatorname{AUTHOR}(S)$ :
}

Zamma, Koichiro

\section{CITATION:}

Zamma, Koichiro. What makes wild chimpanzees wake up at night?. Primates; journal of primatology 2013, 55(1): 51-57

\section{ISSUE DATE:}

2013-07-02

URL:

http://hdl.handle.net/2433/197324

\section{RIGHT:}

The final publication is available at Springer via http://dx.doi.org/10.1007/s10329-0130367-1; この論文は出版社版でありません。引用の際には出版社版をご確認ご利用くだ さい。; This is not the published version. Please cite only the published version. 


\title{
What makes wild chimpanzees wake up at night? Koichiro Zamma ${ }^{1,2,3}$
}

1. Great Ape Research Institute, Hayashibara

2. Graduate School of Asian and African Area Studies, Kyoto University

3. Wildlife Research Center, Kyoto University

\begin{abstract}
I examined the possible cause of night awakening among wild chimpanzees (Pan troglodytes) in Mahale Mountains National Park, Tanzania. Chimpanzee vocalizations and activity-related sounds (CVSs) were used to indicate awakening because I was unable to visually observe them. Over a 5-night observation period, CVSs $(n=128)$ were heard every night, and most $(n=91)$ were observed within 5 min of previous CVSs. Chimpanzees use CVSs as social communication to maintain spatial contact with other chimpanzees who occasionally travel at night. The first sound in a sequence of CVSs (CVS bout) was heard immediately following the vocalization or sound of another animal $(n=11)$, defecation or urination by a chimpanzee $(n=7)$, or unknown $(n=19)$. CVS bouts were longer when preceded by defecation or urination than when preceded by the vocalization or sound of other animals, or an unknown factor. This suggests that the degree of wakefulness varies according to the possible cause of the disturbance. CVSs at night may be provoked by various factors, and awakening during the night is probably common among diurnal primates.
\end{abstract}

Key words: Wild chimpanzee, Night awakening, Vocalization and activity-related sound, Mahale Mountains

\section{Introduction}

Diurnal primates are mostly inactive at night (Rahaman and Parthasarathy 1969, Kinzey et al. 1977, Erffmeyer 1982) and are generally assumed to spend that time sleeping. For example, Hall (1965) reported that patas monkeys (Erythrocebus patas) rested in trees without vocalizing, and Kinzy et al. (1977) reported that yellow-handed titi monkeys (Callicebus torquatus torquatus) did not move from their sleeping branch during the night. As they spend around half of each 24 hour day inactive, within a sleeping site, the selection of these sites based on ecological conditions and choice of members of sleeping clusters based on social parameters, is important (Anderson 1984, 1998, Fruth and McGrew 1998). Most research on sleeping site preferences (Buxton 1951, Lumsden 1951, Sugardjito 1983, Ogawa et al. 2007, Stanford and O'Mally 2008) and sleeping group membership (Struhsaker 1967, Takahashi 1997, Yamagiwa 2001, Ogawa and Takahashi 2003) has been conducted during daylight, at dusk or at dawn.

In order to understand more about sleep-related behaviors in primates, it is necessary to conduct research into their nocturnal behavior. Some research has been conducted during the night and reported that diurnal primates engage in behaviors other than sleeping. Using radio telemetry, Kawai and Iwamoto (1979) revealed that gelada baboons (Theropithecus gelada) sometimes moved at night. Other studies have been 
based on direct observation. Rhesus macaques (Macaca mulatta) played, ate, and copulated at night (Vessey 1973); Barbary macaques (Macaca sylvanus) vocalized at dusk (Hammerschmidt et al. 1994); and Japanese macaques (Macaca fuscata yakui) moved their sleeping sites when sika deer (Cervus nippon yakushimae) approached to eat monkey feces (Nishikawa and Mochida 2010). Orangutans (Pongo pygmaeus), who make beds for sleeping at night, were rarely observed leaving their beds to feed after dark (MacKinnon 1974). Gorillas (Gorilla beringei) were not observed leaving their beds at night, although a silverback male occasionally intermittently beat his chest during the night (Schaller 1963).

Chimpanzees are diurnal primates, make beds in trees, and sleep in these beds at night (Goodall 1962, Izawa and Itani 1966, Stewart et al. 2007). In captivity, chimpanzees do not move much in the dark (Riss and Goodall 1976), although they do make body movements that depend on whether they are in rapid-eye-movement (REM) or non-REM sleep (Freemon et al. 1970). A recent study reported that sleep duration among captive chimpanzees temporarily decreased when they were relocated to an unfamiliar facility (Morimura et al. 2012). Evidence that chimpanzees in the wild waken up during the night has been reported. Chimpanzees have been observed visiting a feeding area at night (Goodall 1968), and searching for food on a moonlit night, possibly related to temperature stress during the day in a hot, dry environment (Pruetz and Bertolani 2009). Goodall (1962) described hearing the sounds of urination and defecation coming from a chimpanzee bed at night. At night, wild chimpanzees utter loud calls and pant hoots in response to the vocalizations of potential predators, such as lions (Panthera leo), leopards (Panthera pardus), and wild dogs (Lycaon pictus) (Tutin et al. 1981). They also utter inter-group calls or loud calls at night, but the reason for this has not been ascertained (Izawa and Itani 1966, Goodall 1968).

Sleep is related to cognition, and lying on a bed, which improves the quality of sleep, is thought to have advanced the cognitive evolution of hominids (Fruth and Hohmann 1996). The finding that the chimpanzees of the Nimba Mountains in Guinea build sleeping beds on the ground suggests that some early hominids may also have slept on the ground (Koops et al. 2012). The choice between a terrestrial and arboreal bed may depend on comfort. Samson and Hunt (2012) investigated the physical comfort levels of tree and ground beds and reported that the microclimate on the ground was homeostatic, and wind speeds were greater than in a tree. However, Stewart (2011) slept in chimpanzee tree beds and on the bare ground and reported that sleeping on the ground was associated with more disturbances (primarily by movements of large terrestrial mammals) than sleeping in a tree.

Previous reports of night vocalizations and behavior have suggested that the sleep of chimpanzees in the wild is disturbed at night. To determine the relation between night vocalization and behavior of chimpanzees and disturbance, I recorded their nocturnal vocalizations and activity-related sounds. I hypothesized that this behavior would be caused by social, environmental, and physiological factors. Social factors include exchanges of vocalizations and sounds related to activities. Chimpanzees sometimes call in response to loud calls made by others during the daytime (Goodall 1968). At night too, chimpanzees may call in response to vocalizations and sounds associated with the activities of others. Environmental factors include disturbances caused by nocturnal animals. In the forest at Mahale Mountains National Park, Tanzania, many animals, including leopards, greater galagos (Otolemur crassicaudatus), thick-tailed galagos 
(Galago senegalensis), bush pigs (Potamochoerus porcus), aardvarks (Orycteropus afer), and giant rats (Cricetomys emini) are active at night (Nishida 1990). The footsteps and vocalizations of these animals and the leopard roars may disturb sleeping chimpanzees. Physiological factors involve the drive to eliminate waste; chimpanzees may get up in the night to defecate or urinate. This paper reports on the frequency with which chimpanzees produce vocalizations and sounds and identifies the possible causes of night awakening.

\section{Methods}

The study was conducted on the M-group in Mahale Mountains National Park, Tanzania. Observations were made over the course of five nights from August 26 to September 2, 2011. The nights were almost completely dark during this period because the new moon fell on August 29, 2011. It was the dry season and no rain fell. The M group of chimpanzees at Mahale has been habituated (Nishida 1990); it comprised 62 individuals at the time of this study (MMCRP unpublished data). Chimpanzees live in a fission-fusion society and travel in parties (Nishida 1968). The mean party size during the study period was 33.6 (range $=21-47$, MMCRP unpublished data).

Data on the vocalizations and sounds made by chimpanzees and other animals were collected. In the evening I followed a party of chimpanzees that I had observed during in the day. I began collecting data when the last chimpanzees in the party finished building a bed (mean start time 19:31, range 18:47-19:51) and stopped when the first chimpanzee in the party left its bed in the morning (mean finish time 6:48, range 6:07-7:13). I rested and did not record data for about 2.0 h each night (range 1.2-3.4 h), thus I excluded the time from the data analysis. Total observation time was $46.4 \mathrm{~h}$. I set the observation point on the ground about $30 \mathrm{~m}$ from the trees where the chimpanzees built their beds; however, some chimpanzees arrived late and built beds around the observation point after dark. I sat alone at the observation point through the night and collected data on the entire group. To avoid disturbing the chimpanzees, I used a small flashlight covered with four layers of colored plastic film (red, yellow, green, and blue). Although the light was too dim for reading, it was sufficient to briefly find a blank space on a page in my notebook and then write in the blank without looking. I also used infrared imaging devices (Sony DCR-TRV8, Sony HDR-XR500, and Hoga IRL-C5-170-880 to observe chimpanzees and other animals on the ground; however, I did not use the video data because the observation point was below the beds, making it difficult to clearly record chimpanzees in trees. I could not use direct observation to assess awakenings of chimpanzees, so I used chimpanzee vocalizations and activity-related sounds (CVSs) to indicate wakefulness.

Several types of CVSs have been described (e. g. Goodall 1989, Nishida et al. 2010); those recorded during the study period were categorized into four vocalizations (pant hoots, loud calls [bark, wraa, and pant grunt], bed grunts, and soft calls [cough, "huum" and "hu"]) and three activity sounds (display and locomotion, bed-building, and other sounds [kicking, knocking, and clacking something between the teeth]). The sound of swaying branches was excluded from the analysis because it was not clear whether this was caused by the chimpanzees, other animals, or the wind. Each chimpanzee makes a new bed each night (Goodall 1962), and several chimpanzees form a nesting group (Goodall 1968). Because chimpanzees made their beds within a small area, the precise 
individuals vocalizing and making sounds could not be identified. CVSs made by several individuals at the same time were treated as a single event.

I recorded the frequency and time at which various CVSs and other sounds occurred during the night and determined whether the frequency of CVSs differed over the course of the night. Furthermore, I recorded the frequency of vocalizations and sounds made by other animals, the sound of chimpanzees defecating and urinating, and the sound of human activity and the time they occurred to determine whether the CVSs correlated with these vocalizations and sounds.

CVSs observed within 5 min of a previous CVS were considered to depend on the previous activity; the sequence was thus defined as a CVS bout. If vocalizations made by other animals or animal footsteps were heard within $5 \mathrm{~min}$ before the CVS, an environmental factor was regarded as the cause of the CVS, whereas if the sound of defecation or urination was heard before the chimpanzee sound, a physiological factor was regarded as the cause. If no sound was heard within 5 min before the chimpanzee sound, the cause was regarded as unknown.

Statistical tests were conducted using R 2.15.0 software (R Development Core Team 2012). The Kolmogorov-Smirnov test was performed to evaluate if variables were normally distributed. To investigate differences in the frequency of CVSs among time of night, the frequency of CVSs was calculated as the number of CVSs per hour per day, and was analyzed using the Kruskal-Wallis test. Kendall's rank correlation was used to determine the correlation between the CVSs and the other sounds and vocalizations. The differences in CVS bout duration in response to environmental, physiological, and unknown factors were analyzed using the Kruskal-Wallis test followed by the Steel-Dwass test for multiple comparisons.

\section{Results}

\section{Time of night awakening}

CVSs occurred every night $(n=128)$. At dusk, bed grunts and the sounds of bed-making were more frequent, whereas at midnight and dawn, pant hoots were heard more frequently. The frequency of CVSs did not differ across the time of night (Kruskal-Wallis test, $H=6.1, d f=13 ; P=0.94$ ).

Animal vocalizations and sounds related to their activity $(n=109)$ were heard throughout the night (Fig. 2). The footsteps of nocturnal mammals $(n=52)$ were also heard but, except for two species (bush pigs and giant rats) recorded by the infrared video device, most were difficult to identify. Vocalizations of greater galagos $(n=29)$ were heard every night, those of yellow baboons (Papio cynocephalus, $n=3$ ) during two nights, and those of red colobus (Procolobus badius, $n=1$ ) during only one night. A leopard vocalization was heard once. The songs of the nightjar (Caprimulgidae) and morning birds were also heard. Unlike the sounds of other animals, these bird songs were continuous, so I recorded the start time of the first sounds $(n=16)$. The sounds of chimpanzee defecation and urination $(n=78)$ were heard most often at midnight and dawn. Sounds of human activity $(n=23)$, such as vehicle noises and the voices of staff in the park village, were also heard, but less frequently. No significant correlation was found between these vocalizations and sounds and CVSs (Kendall's rank correlation, animal: $\tau$ 
$=-0.16, P=0.11$, defecation and urination: $\tau=0.16, P=0.13$, human: $\tau=-0.05, P=$ $0.64)$.

\section{Sequence of chimpanzee sounds}

Chimpanzees exchanged vocalizations at night; many of the sounds $(n=91)$ were heard within 5 min of previous sounds (Fig. 3). Pant hoots were heard most often after previous pant hoots (Table 1). Bed grunts were heard after the sounds of bed-making or other bed grunts, and the sounds of displays and locomotion were heard after pant hoots and prior sounds of displays and locomotion.

\section{Relationship of Disturbances to CVS}

Thirty-seven bouts were extracted from the data. These had a mean $\pm S D$ duration of $3.6 \pm 5.8$ (range 0-22) minutes. Possible causes that occurred within the 5 minutes before the first sound in a bout, were environmental $(n=11)$, physiological $(n=7)$, or unknown $(n=19)$. The durations of bouts differed significantly according to the previous sound (Kruskal-Wallis test, $H=10.4, d f=2, P=0.006$ ); bouts followed by physiological factors lasted longer than those followed by environmental or unknown factors (Steel-Dwass multiple comparison, Fig. 4).

Pant hoots were more likely observed following physiological factors (Table 2). In comparison, soft calls and bed grunts were observed after environmental factors, which included greater galago vocalizations $(n=5)$, sounds of animal footsteps $(n=4)$, vocalizations by unknown species $(n=1)$, and songs of birds $(n=1)$. Chimpanzees did not respond to yellow baboon or red colobus vocalizations, whereas they called loudly for about 1 min when a leopard roared from a distance of about $200 \mathrm{~m}$ during a bout that started with a bed grunt. The vocalizations followed by unknown factors consisted of pant hoots, bed grunts, and soft calls.

Five cases of chimpanzee defecation and urination sounds were observed within 5 min after CVS bouts. These CVS bouts was lasted 2.8 (range $=0-6) \mathrm{min}$.

\section{Discussion}

The vocalizations and sounds of activity of the chimpanzees were heard during every night of the study period. This suggests that chimpanzees's sleep is frequently disrupted. As noted in previous studies (Goodall 1968, Izawa and Itani 1966), pant hoots were the most frequent chimpanzee vocalization during the night. One function of the pant hoot is to maintain spatial contact with others (Mitani and Nishida 1993). Chimpanzees occasionally travel at night (Goodall 1968, Izawa and Itani 1966, Pruetz and Bertolani 2009). They may emit vocalizations to monitor the location of group members, and subsequent vocalizations may be in reply to a previous call. I could not determine whether the replying chimpanzees were awakened by the previous call or by other stimuli; CVSs are one source of disturbance in the night (Stewart 2011); however, chimpanzees may also be awakened by the disturbances of other chimpanzees. Gorillas occasionally exchange chest-beating signals at night (Schaller 1963). Social communication may be a cause of African apes waking up at night.

The frequency of CVS did not vary significantly through the night. However, aspects such as duration or the composition of CVS varied with the cause of the disturbance. Chimpanzees were more likely to utter pant hoots after defecation and 
urination, and these long-distance calls triggered other CVSs lasting for several minutes. Chimpanzees are careful to defecate or urinate over the edge of the bed at night (Goodall 1962). While assuming the appropriate position on the edge of the arboreal bed, some chimpanzees may have become fully awake. Alert chimpanzees that had been alone since the previous evening may utter pant hoots to maintain contact with neighboring chimpanzees (Mitani and Nishida 1993). Furthermore, defecation and urination sounds were heard a few minutes after a CVS bout, suggesting that some chimpanzees awakened by a previous CVS evacuate occasionally.

Various other animal vocalizations and the sound of footsteps also elicited responses from the chimpanzees, but these were of short duration and the vocalizations were softer calls (bed grunts and soft calls). It is not unusual for Mahale chimpanzees to hear sounds made by nocturnal animals, only few of which are dangerous. Chimpanzees awakened by the sound of an animal may utter soft vocalizations to relax the tension when they realize that the animal is not dangerous. In comparison, a leopard roar provoked an intense reaction from the chimpanzees at another site (Tutin et al. 1981). Although no evidence of leopard predation on chimpanzees has been reported in Mahale (Nishida 2012, Nishida et al. 2003), the leopard is a potential chimpanzee predator and has been reported to attack and kill chimpanzees (Boesch 1991, Boesch and Boesch-Achermann 2000). Chimpanzees may emit loud vocalizations to signal that the predator has been detected and to discourage it from hunting (Boesch and Boesch-Achermann 2000, Tutin et al. 1981). Thus, chimpanzees utter loud calls in response to leopards during the night (Tutin et al. 1981, this study) as well as during the day (Boesch 1991, Hiraiwa-Hasegawa et al. 1986, Nishida 2012, Pierce 2009).

In the present study, more than half of the sounds that elicited a CVS bout were unidentified. In some cases, chimpanzees suddenly made bed-making sounds; they may have been remaking or repairing their bed because it was uncomfortable (Goodall 1962). Some vocalizations were uttered without any apparent eliciting event. Stewart (2011) reported that she was disturbed by arboreal animal noises when she slept in an arboreal bed in Fongoli, Senegal. The chimpanzees of Mahale may also have been disturbed by the noise of arboreal animals that I could not hear because of the distance.

Primates, including chimpanzees, are more active on moonlit nights (chimpanzee: Goodall 1968, Izawa and Itani 1966; rhesus monkey: Vessey 1973). Chimpanzees in Fongli have been observed travelling up to $1 \mathrm{~km}$ on a brightly moonlit night (Pruets and Bertolani 2009), and I observed chimpanzees walking on the ground on a moonlit night in Mahale in 2011 (Zamma unpublished data). However, the present study demonstrates that chimpanzees also wake up during the night in response to physiological and environmental factors (see also Nishikawa and Mochida 2010) unrelated to moonlight. These results provide further evidence that awaking during the night is not an exceptional event and may be common in diurnal primates.

\section{Acknowledgments}

I thank the Tanzania Wildlife Research Institute (TAWIRI) Tanzania National Park (TANAPA), and Tanzania Commission for Science and Technology(COSTECH) for permission to conduct the fieldwork, T. Nemoto, G. Idani, H. Kishi, K. Kimura, H. Kobayashi, A. Saito, Y. Sakuraba, M. Seres, M. Shikuwa, N. Takagi, S. Ueda, and N. Yamashita for helping me to visit the research site, and H. Ihobe, T. Matsumoto M. 
Shimada, and other member of Mahale Mountains Chimpanzee Research Project (MMCRP) for their help in the field. The paper benefited much from the comments of two anonymous referees. I also thank $M$. Uchikoshi and C. Tokimatsu for their valuable assistance and N. Takagi, K. Takarada, K. Mochida, and M. Nishikawa for their advice on the night behavior of animals.

\section{References}

Anderson JR (1984) Ethology and ecology of sleep in monkeys and apes. Adv Stud Behav 14:165-229

Anderson JR (1998) Sleep, sleeping sites, and sleep-related activities: awakening to their significance. Am J Primatol 46:63-75

Boesch C (1991) The effects of leopard predation on grouping patterns in forest chimpanzees. Behaviour 117:220-242

Boesch C, Boesch-H (2000) The chimpanzees of the Tai Forest: behavioural ecology and evolution. Oxford University Press, Oxford

Buxton AP (1951) Further observations of the night-resting habits of monkeys in a small area on the edge of the Semliki Forest, Uganda. J Anim Ecol 20:31-32

Erffmeyer ES (1982) The nocturnal behavior of caged rhesus monkeys (Macaca mulatta). Folia Primatol 38:240-249

Freemon FR, McNew JJ, Adey WR (1970) Sleep of unrestrained chimpanzee: differences between first and last rapid eye movement periods. Folia Primatol 13:144-149

Fruth B, Hohmann G (1996) Nest building behavior in the great apes: the great leap forward? In: McGrew WC, Marchant L, Nishida T (eds) Great Ape Societies, Cambridge University Press, Cambridge, pp 225-240

Fruth B, McGrew WC (1998) Resting and nesting in primates: behavioral ecology of inactivity. Am J Primatol 46:3-5

Goodall J (1962) Nest building behavior in the free ranging chimpanzee. Ann NY Acad Sci 102:455-467

Goodall J (1968) The behaviour of free-living chimpanzees in the Gombe Stream Reserve. Anim Behav Monogr 1:165-311

Goodall J (1986) The chimpanzees of Gombe: patterns of behavior. The Belknap Press of Harvard University Press, Cambridge

Goodall J (1989) Glossary of chimpanzee behaviors. Jane Goodall Institute, Tucson, AZ

Hall KRL (1966) Behaviour and ecology of the wild patas monkey, Erythrocebus patas, in Uganda. J. Zool. 148:15-87

Hammerschmidt K, Ansorge V, Fischer J, Todt D (1994) Dusk calling in Barbary macaques (Macaca sylvanus): Demand for social shelter. Am J Primatol $32: 277-289$

Hiraiwa-Hasegawa M, Byrne RW, Takasaki H, Byrne JME (1986) Aggression toward large carnivores by wild chimpanzees of Mahale Mountains National Park, Tanzania. Folia Primatol 47:8-13

Izawa K, Itani J (1966) Chimpanzees in Kasakati Basin, Tanganyika (1) Ecological study in the rainy season 1963-1964. Kyoto Univ Afr Stud 1:73-156

Kawai M and Iwamoto T (1979) Nomadism and activities. In Kawai M (ed) Ecological and sociological studies of gelada baboons. Karger, Basel, pp 251-278

Kinzey WG, Rosenberger AL, Heisler PS, Prowse DL, Trilling JS (1977) A preliminary 
field investigation of the yellow handed titi monkey, Callicebus torquatus torquatus, in northern Peru. Primates 18:159-181

Koops K, McGrew WC, Matsuzawa T, Knapp LA (2012) Terrestrial nest-building by wild chimpanzees (Pan troglodytes): implications for the tree-to-ground sleep transition in early hominins. Am J Phys Anthropol 148:351-361.

Lumsden WHR (1951) The night-resting habits of monkeys in a small area on the edge of the Semliki Forest, Uganda. A study in relation to the epidemiology of Sylvan yellow fever. J Anim Ecol 20:11-30

MacKinnon J (1974) The behaviour and ecology of wild orang-utans (Pongo Pygmaeus). Anim Behav 22:3-74

Mitani JC, Nishida T (1993) Contexts and social correlates of long-distance calling by male chimpanzees. Anim Behav 45:735-746

Morimura N, Fujisawa M, Mori Y, Teramoto M (2012) Environmental influences on sleep behavior in captive male chimpanzees (Pan troglodytes). Int $\mathrm{J}$ Primatol 33:822-829

Nishida T (1968) The social group of wild chimpanzees in the Mahali Mountains. Primates 9:167-224

Nishida T (1973) The ant-gathering behaviour by the use of tools among wild chimpanzees of the Mahali Mountains. J Hum Evol 2:357-370

Nishida T (1990) A quarter century of research in the Mahale Mountains: an overview. In: Nishida T (ed) The chimpanzees of the Mahale Mountains: sexual and life history strategies, University of Tokyo Press, Tokyo, pp 285-290

Nishida T (2012) Chimpanzees of the Lakeshore: Natural History and Culture at Mahale. Cambridge University Press, Cambridge

Nishida T, Corp N, Hamai M, Hasegawa T, Hiraiwa-Hasegawa M, Hosaka K, Hunt KD, Itoh N, Kawanaka K, Matsumoto-Oda A, Mitani JC, Nakamura M, Norikoshi K, Sakamaki T, Turner L, Uehara S, Zamma K (2003) Demography, female life history and reproductive profiles among the chimpanzees of Mahale. Am J Primatol 59(3):99-121

Nishida T, Zamma K, Matsusaka T, Inaba A, McGrew WC (2010) Chimpanzee Behavior in the Wild: An Audio-Visual Encyclopedia. Springer, Tokyo

Nishikawa M, Mochida K (2010) Coprophagy-related interspecific nocturnal interactions between Japanese macaques (Macaca fuscata yakui) and sika deer (Cervus Nippon yakushimae). Primates 51:95-99

Ogawa H, Takahashi H (2003) Triadic positions of Tibetan macaques huddling at a sleeping site. Int J Primatol 24:591-606

Ogawa H, Idani G, Moore J, Pintea L, Hernandez-Aguilar A (2007) Sleeping parties and nest distribution of chimpanzees in the savanna woodland, Ugalla, Tanzania. Int $\mathbf{J}$ Primatol 28:1397-1412

Pierce AH (2009) An encounter between a leopard and a group of chimpanzees at Gombe National Park. Pan Afr News 16:22-24

Pruetz, JD, Bertolani P (2009) Chimpanzee (Pan troglodytes verus) behavioral responses to stresses associated with living in a savanna-mosaic environment: implications for hominin adaptations to open habitats. PaleoAnthropol 2009:252-262.

R Development Core Team (2012) R: A language and environment for statistical computing. R Foundation for Statistical Computing, Vienna, Austria. ISBN 3-900051-07-0, URL http://www.R-project.org/ 
Rahaman H, Parthasarathy MD (1969) Studies on the social behaviour of bonnet monkeys. Primates 10:149-162

Samson DR, Hunt KD (2012) A thermodynamic comparison of arboreal and terrestrial sleeping sites for dry-habitat chimpanzees (Pan troglodytes schweinfurthii) at the Toro-Semliki Wildlife Reserve, Uganda. Am J Primatol 74:811-818

Schaller G (1963) The mountain gorilla: ecology and behavior. The University of Chicago Press, Chicago

Stanford CB, O’Malley RC (2008) Sleeping tree choice by Bwindi chimpanzees. Am J Primatol 70:642-649

Stewart FA (2011) Brief communication: Why sleep in a nest? Empirical testing of the function of simple shelters made by wild chimpanzees. Am J Phys Anthropol 146:313-318.

Stewart FA, Pruetz JD, Hansell MH (2007) Do chimpanzees build comfortable nests? Am J Primatol 69:930-939

Struhsaker TT (1967) Social structure among vervet monkeys. Behaviour 29:83-121

Sugardjito J (1983) Selecting nest-sites of Sumatran orang-utans, Pongo pygmaeus abelii in the Gunung Leuser National Park, Indonesia. Primates 24:467-474

Takahashi H (1997) Huddling relationships in night sleeping groups among wild Japanese macaques in Kinkazan Island during winter. Primates 38:57-68

Tutin CEG, McGrew WC, Baldwin PJ (1981) Responses of wild chimpanzees to potential predators. In: Chiarelli AB, Corruccini RS (eds) Primate behavior and sociobiology, Springer-Verlag, Berlin and New York, pp 136-141

Vessey SH (1973) Night observations of free-ranging rhesus monkeys. Am J Phys Anthropol 38:613-620

Yamagiwa J (2001) Factors influencing the formation of ground nests by eastern lowland gorillas in Kahuzi-Biega National Park: some evolutionary implications of nesting behavior. J Hum Evol 40:99-109 
Table 1. Number of vocalizations and activity-related sounds of chimpanzees that occurred within 5 minutes following other vocalisations or activity-related sounds of chimpanzees.

\begin{tabular}{|c|c|c|c|c|c|c|c|c|}
\hline \multirow[b]{2}{*}{ Before } & \multicolumn{7}{|c|}{ After } & \multirow[b]{2}{*}{ total } \\
\hline & pant hoot & loud call & bed grunt & soft call & $\begin{array}{l}\text { display and } \\
\text { locomotion }\end{array}$ & making bed & $\begin{array}{c}\text { other } \\
\text { activity }\end{array}$ & \\
\hline pant hoot & 37 & 5 & 1 & 6 & 2 & 0 & 1 & 52 \\
\hline loud call & 4 & 1 & 0 & 1 & 0 & 1 & 0 & 7 \\
\hline bed grunt & 1 & 1 & 5 & 1 & 0 & 4 & 0 & 12 \\
\hline soft call & 5 & 1 & 0 & 3 & 0 & 1 & 0 & 10 \\
\hline $\begin{array}{l}\text { display and } \\
\text { locomotion }\end{array}$ & 3 & 0 & 0 & 0 & 0 & 0 & 0 & 3 \\
\hline making bed & 0 & 0 & 5 & 0 & 0 & 1 & 0 & 6 \\
\hline $\begin{array}{l}\text { other } \\
\text { activity }\end{array}$ & 0 & 0 & 0 & 1 & 0 & 0 & 0 & 1 \\
\hline total & 50 & 8 & 11 & 12 & 2 & 7 & 1 & 91 \\
\hline
\end{tabular}

Table 2. Number of chimpanzee vocalizations and activity-related sounds that occurred within 5 minutes of each possible causal factor.

\begin{tabular}{lcccc}
\hline & $\begin{array}{c}\text { Physiological } \\
\text { factor }\end{array}$ & $\begin{array}{c}\text { Environmental } \\
\text { factor }\end{array}$ & $\begin{array}{c}\text { Unknown } \\
\text { factor }\end{array}$ & total \\
\hline pant hoot & 38 & 7 & 13 & 58 \\
loud call & 5 & 1 & 2 & 8 \\
bed grunt & 2 & 5 & 16 & 23 \\
soft call & 8 & 8 & 9 & 25 \\
display and & 3 & 0 & 0 & 3 \\
locomotion & 1 & 0 & 8 & 9 \\
making bed & 1 & 0 & 1 & 2 \\
other activity & 58 & 21 & 49 & 128 \\
\hline total & & & & \\
\hline
\end{tabular}




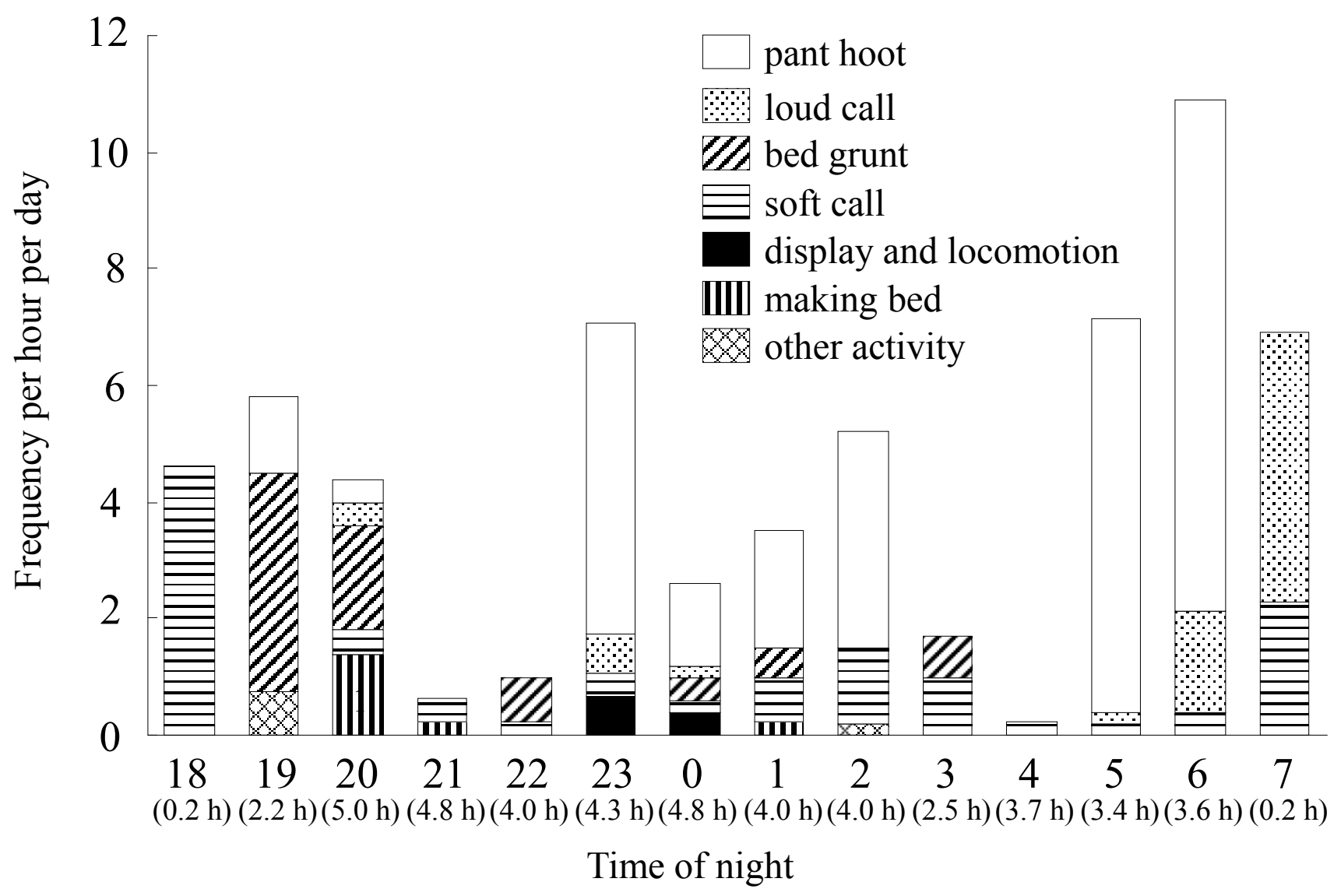

Figure 1. Frequency of chimpanzee vocalizations and activity-related sounds at night.

The value of each bar is mean frequency per hour per day. Numbers in parentheses indicate observation hours of each time of night. 


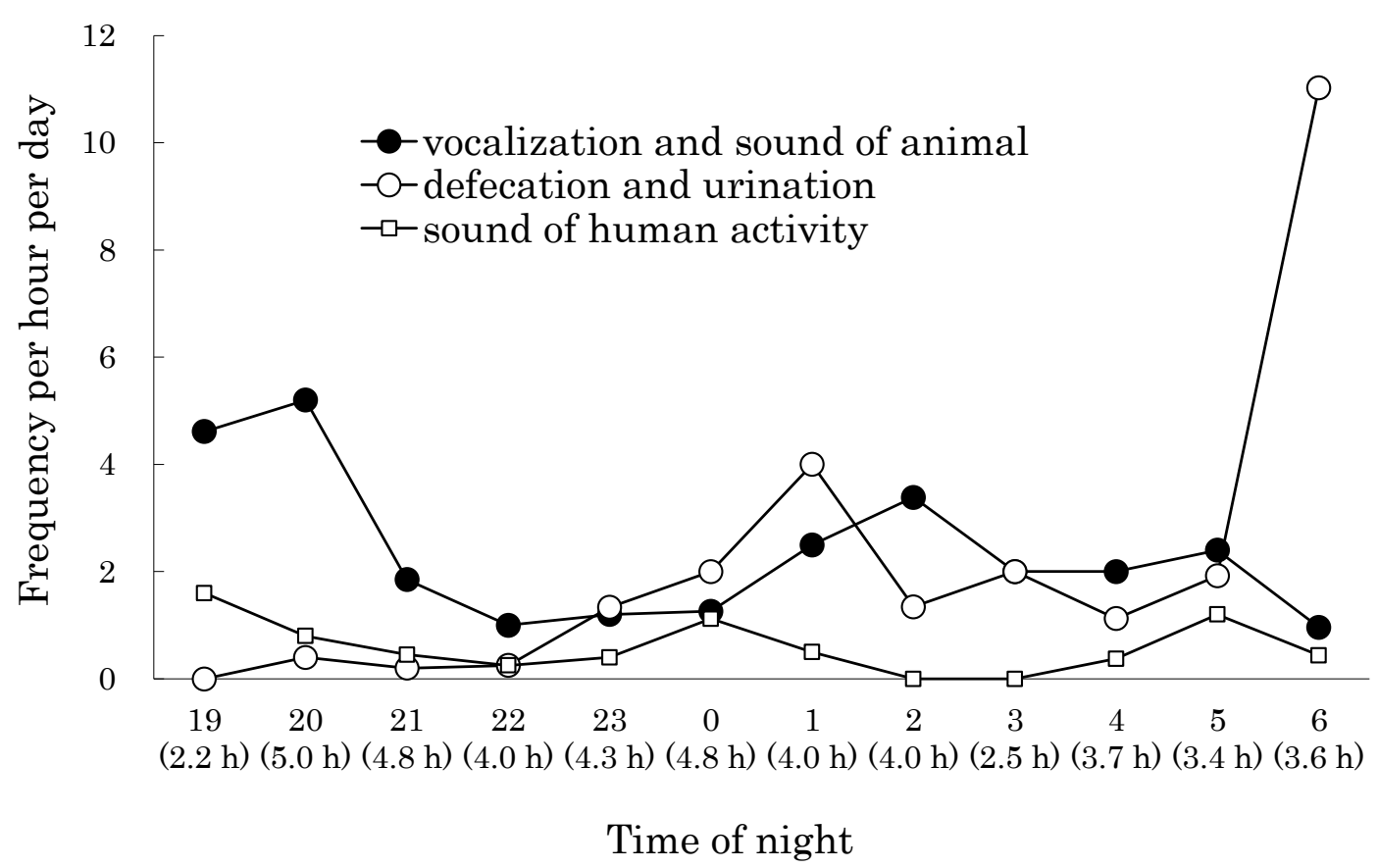

Figure 2. Frequency of the sounds of chimpanzee defecation or urination (open circles), animal vocalizations and sounds of activity (closed circles), and sounds of human activity and voices (open squares) at night. The value is mean frequency per hour per day. Numbers in parentheses indicate observation hours of each time of night. 


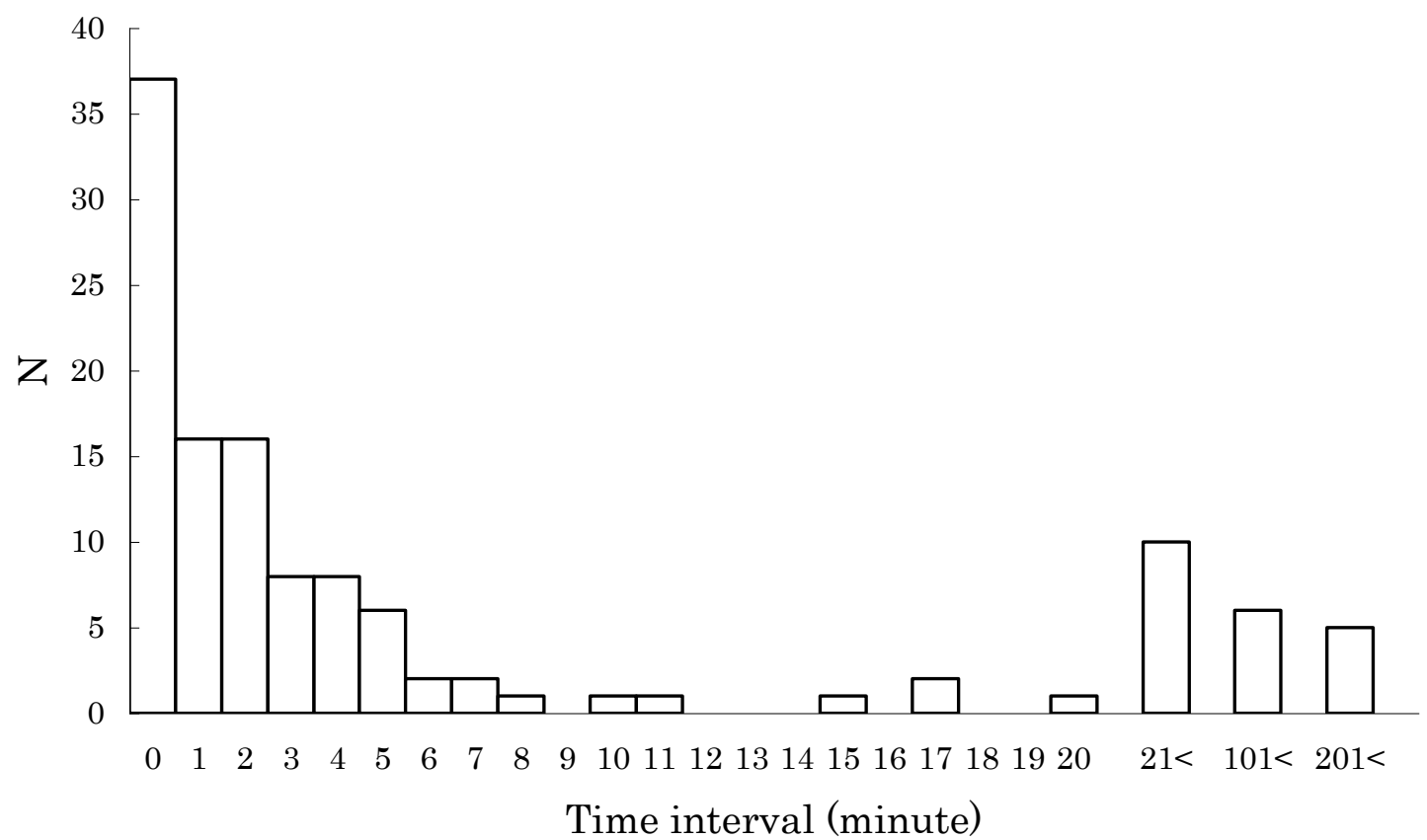

Figure 3. Time intervals between previous and next chimpanzee vocalizations and activity-related sounds (CVS). 


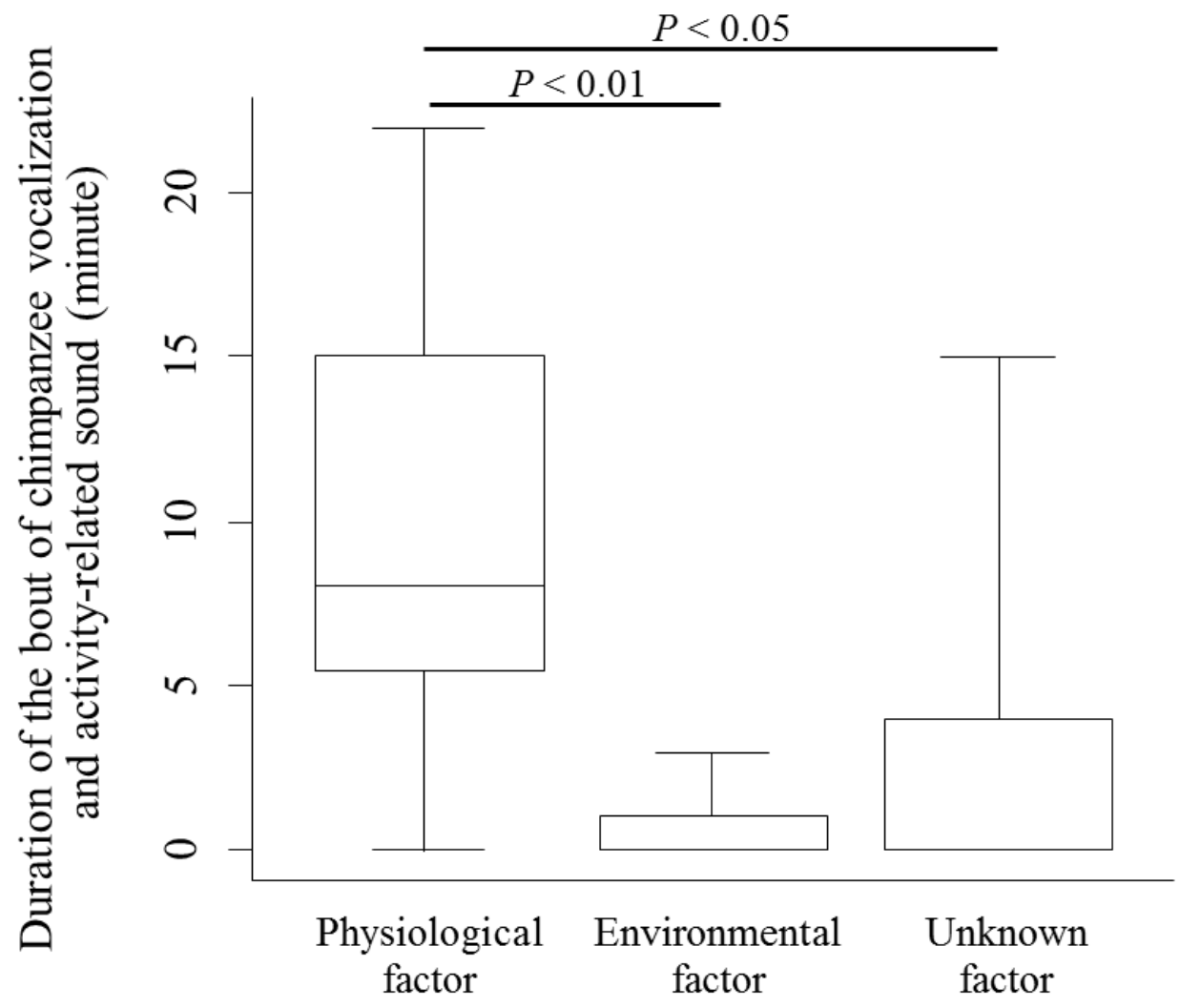

Figure 4. Duration of bouts of chimpanzee vocalizations and activity-related sounds (CVS) caused by physiological $(n=7)$, environmental $(n=11)$, and unknown $(n=19)$ factors. The bottom and top of the box means the lower and upper quartile, and the band in the box means median. The end of the whiskers means the minimum and maximum of the data. The median, lower quartile, and the minimum duration of CVS preceded by environmental and unknown factor was 0 . There were significant differences in duration of CVS between physiological and environmental factor (Steel-Dwass multiple comparison, $P<0.01)$, and between physiological and unknown factor $(P<0.05)$. 